\title{
A Discussion of Stability and Engineering Verification of Thin Immediate Roof under Uniform Load of the Rectangular Coal Roadway
}

\author{
Linsheng Gao, ${ }^{1,2}$ Yueping Wang ${ }^{D},{ }^{2}$ Er-hui Zhang, ${ }^{2}$ Liang Cheng, ${ }^{3}$ and Rui Peng ${ }^{2}{ }^{2}$ \\ ${ }^{1}$ School of Mineral Engineering, Xi'an University of Science and Technology, Xi'an, Shanxi 710054, China \\ ${ }^{2}$ School of Safety Engineering, North China Institute of Science and Technology, Beijing 101601, China \\ ${ }^{3}$ Zhongshan Haofa Real Estate Development Co., Ltd., Zhongshan, Guangzhou 528400, China \\ Correspondence should be addressed to Yueping Wang; ypwang@ncist.edu.cn
}

Received 26 June 2020; Revised 20 August 2020; Accepted 20 September 2020; Published 28 October 2020

Academic Editor: Zhiqiang Yin

Copyright (C) 2020 Linsheng Gao et al. This is an open access article distributed under the Creative Commons Attribution License, which permits unrestricted use, distribution, and reproduction in any medium, provided the original work is properly cited.

Roadway roof is a key factor in roadway stability. At present, the analysis of roof stability is mainly based on numerical calculations and field measurements with a relatively weak theoretical basis and inadequate research studies on the loading mechanism of the roof. In this paper, a mechanical calculation model of immediate direct roof under uniform load of rectangular coal roadway is established. The stress distribution and roof subsidence in the roof are calculated theoretically and verified by the numerical calculation, physical tests, and engineering applications. Based on the classical beam solution theory, the stress distribution and sinking of the thin immediate roof under uniform load are obtained and verified by numerical calculations. The results are highly consistent. Two types of thin direct roof failure under uniform load are analyzed: the failure of the normal cross section caused by the bottom tensile stress and the failure of the inclined section caused by the combined effect of the tensile stress in the abdominal area and compressive stress. The stability of thin immediate roof under uniform load of the rectangular coal roadway was tested in 1905 s mining roadway of Great Wall Number \#3 coal excavation field. This research can further fill in blanks of the loading mechanism of the roadway roof and provide theoretical and pragmatic values to control the roadway pressure and rock stratum as well as the scientific references to the design of the anchor bolt supporting system.

\section{Introduction}

In coal mining, the stability of the roadway roof is one of the keys to ensure the safe and efficient production of the mine. However, the existing researches fail to provide a clear stability mechanism and sufficient theories about the supporting system for the roadway roof [1-5]. In the initial study of the roadway surrounding rock stability, the self-supporting capacity of the surrounding rock was often neglected. The bolt support plays a role of suspension or provides support resistance to the surface of the roadway $[1,6,7]$. With the development of anchor bolt technology, people gradually recognize that the pressure of the roadway surrounding rock has been mainly born by the surrounding rock itself with the surrounding rock as the primary load carrier and the supporting system as the secondary load carrier $[8,9]$. The bearing capacity of the surrounding rock of the roadway was firstly proposed in the Terzaghi theory [10]. The Protodyakonov theory [11] suggests that the pressure imposed on the supporting system originated from the weight of loose rocks in the collapse arch of the surrounding rock. The Austrian method [12] theory indicates that the self-bearing capacity of the surrounding rock plays a dominating role in achieving the stability of the surrounding rock. The core idea of the Austrian method lies in making use of the self-bearing capacity of the surrounding rock to support the roadway surrounding rock, forming a combined support system along with the external supporting structure through focusing on the self-bearing capacity of the surrounding rock [13].

As the researches regarding the stability of the roadway surrounding rock develop further, people are aware of 
certain load bearing structure included in the roadway surrounding rock, which benefits the optimization of the roadway surrounding rock [14]. Salamon et al. proposed the energy supporting theory, suggesting that supporting structure and surrounding rock of a roadway interact with each other and deformed together. Man-chu [15] conducted the discontinuous deformation analysis (DDA) and found out that the alternate layout of the high preloaded long and short anchor bolts was critical to achieve the supporting structure with high stability. In addition, the anchor bolts in radial pattern can achieve a better control of the roadway roof than those in vertical pattern. Chen et al. [16] believe that the surrounding rock has substantial self-bearing capacity, indicating the limited supporting role of the external supporting structure. Many factors can contribute to the pressure of the surrounding rock including the embedded depth of the tunnel, the tunnel sizes and shapes, the physicomechanical properties, and the flexibilities of the supporting system. Zhao et al. [17] analyze the constraint of the anchor bolts to the expandability of the tunnel rocks through analyzing the interaction between the rock mass dilatancy and bolt support in underground engineering and suggest that the anchor bolt supporting system can effectively improve the pressure environment adjacent to the tunnel and inhibit the expansion of highly pressurized rocks in the area with low pressure.

Improvements are needed in the present researches. All research results fail to include the strength parameters of the coal body, which tends to impact the load bearing capacity of the surrounding rock. Some parameters cannot be obtained, resulting in the gap between the theories and the field applications. Without the quantitate versification, the accuracy is questionable. In this paper, a mechanical calculation model of thin direct roof under uniform load of rectangular coal roadway is established to analyze the mechanism behind the roof collapse. In addition, the results were applied to the field for verification.

\section{Stress Theoretical Calculation of the Thin Immediate Roof under Uniform Load of Rectangular Coal Roadway}

2.1. Theoretical Calculation Model. The thin immediate roof of the roadway, as the study object, bears the evenly distributed load from the top, which often originates from the weight of the top rock layer, with the lateral horizontal stresses at both sides. The roof also bears the vertical stress and shear stress imposed by the coal body. The stress distribution firstly increased and decreased subsequently from the roadway center to the sides, which is equivalent to the bearing loads and stresses mentioned in Section 3, with different orientations [18]. The thin immediate roof under uniform load is considered as a beam structure under the plane stresses, as demonstrated in Figure 1.

The load imposed on the thin immediate roof by the coal body can be calculated based on equation (1). However, compared with the coordinates in Figure 1, the coordinates in Figure 2 moved by $b / 2$ in length to the left, which results in a new equation to calculate the load imposed on the thin immediate roof by the coal body, provided as follows [19]:

$$
\begin{aligned}
& \sigma_{y}=\left[\frac{C_{0}}{\tan \varphi_{0}}+\left(\frac{1+\sin \varphi}{1-\sin \varphi}\right) P_{x}+\frac{2 C \cos \varphi}{1-\sin \varphi}\right] \exp \left[\frac{2 \tan \varphi_{0}(1+\sin \varphi)}{m(1-\sin \varphi)} x\right]-\frac{C_{0}}{\tan \varphi_{0}} \\
& \tau_{x y}=\left[C_{0}+\left(\frac{1+\sin \varphi}{1-\sin \varphi}\right) P_{x} \tan \varphi_{0}+\frac{2 C \cos \varphi \tan \varphi_{0}}{1-\sin \varphi}\right] \exp \left[\frac{2 \tan \varphi_{0}(1+\sin \varphi)}{m(1-\sin \varphi)} x\right] \text {, } \\
& \sigma_{y}= \begin{cases}0, & \left(0 \leq x<\frac{b}{2}\right), \\
K_{1} \exp \left[K_{2}\left(x-\frac{b}{2}\right)\right]-\frac{C_{0}}{\tan \varphi_{0}}, & \left(\frac{b}{2} \leq x \leq x_{0}\right),\end{cases} \\
& \sigma_{y e}=\left(k_{0}-1\right) \gamma H \exp \left[-\alpha\left(x-x_{0}\right)\right]+\gamma H ; \quad\left(x>x_{0}\right) \text {, }
\end{aligned}
$$

where $x_{0}=x_{s}+b / 2 ; K_{1}=C_{0} / \tan \varphi_{0}+(1+\sin \varphi / 1-\sin \varphi)$ $P_{x}+2 C \cos \varphi / 1-\sin \varphi ;$ and $K_{2}=2 \tan \varphi_{0}(1+\sin \varphi) / m(1-$ $\sin \varphi)$.

\subsection{Calculation}

2.2.1. Load Intensity, Shear Force, and Moment of the Thin Immediate Roof under Uniform Load of Rectangular Coal Roadway. In contrast with the classic beam theory, the thin immediate roof under uniform load bears not only the vertical load but also the shear stress load at the bottom due to the lateral coal body [20]. Figure 2 demonstrates a magnified section at $x$ point from the original point, which was selected from the beam shown in Figure 1. $F_{q}$ and $M_{q}$ refer to shear force of the left cross section and the moment, respectively. When $x$ was increased by $\mathrm{d} x, F_{q}$ and $M_{q}$ were increased by $\mathrm{d} F_{q}$ and $\mathrm{d} M_{q}$ accordingly.

All internal forces included in the selected section are taken to be positive. Following $\sum F_{q}=0$ and $\sum M_{q}=0$, the following equation is obtained: 


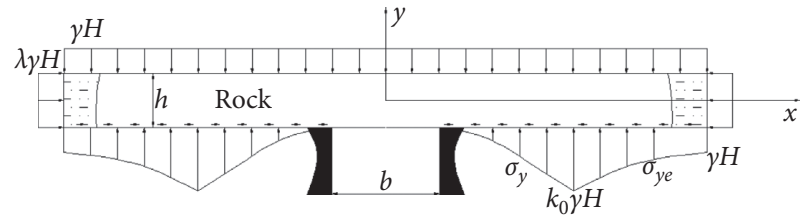

Figure 1: Mechanical model of thin immediate roof.

$$
\begin{array}{r}
F-(F+\mathrm{d} F)+\left(\sigma_{y}-\gamma H\right) \mathrm{d} x=0, \\
-M+(M+\mathrm{d} M)-F \mathrm{~d} x-\left(\sigma_{y}-\gamma H\right) \mathrm{d} x \frac{\mathrm{d} x}{2}+\tau_{x y} \frac{h}{2} \mathrm{~d} x=0
\end{array}
$$

where $M$ is the center moment of the thin immediate roof, $\mathrm{N} \cdot \mathrm{m}$ and $h$ is the thickness of the thin immediate roof $m$.

After skipping the high-order trace $\left(\sigma_{y}-\gamma H\right) \mathrm{d} x(\mathrm{~d} x / 2)$, the internal forces can be expressed as follows:

$$
\begin{gathered}
\frac{\mathrm{d} F}{\mathrm{~d} x}=\sigma_{y}-\gamma H, \\
\frac{\mathrm{d} M}{\mathrm{~d} x}=F-\tau_{x y} \frac{h}{2} .
\end{gathered}
$$

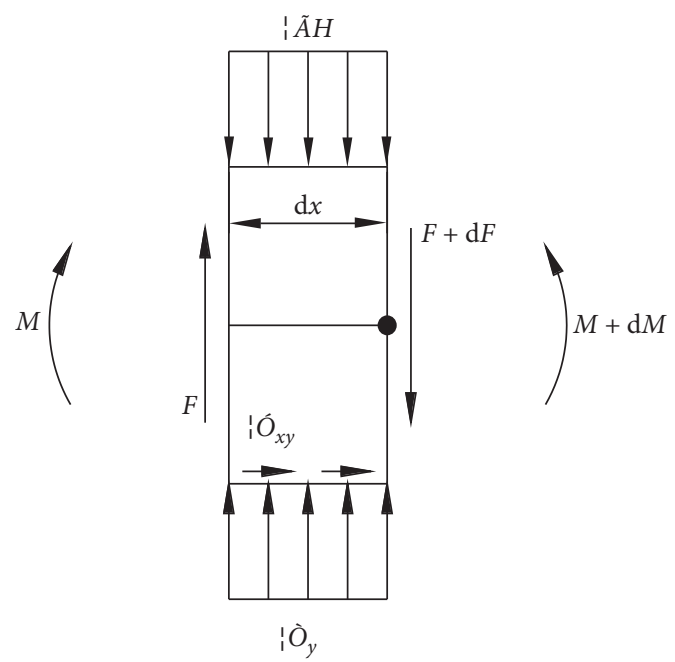

FIGURE 2: The model of the relationship of internal forces of thin immediate roof.

2.2.2. Horizontal Stress of the Thin Immediate Roof under Uniform Load of Rectangular Coal Roadway. According to equation (4), the internal shear force of the thin immediate roof under uniform load can be expressed as follows:

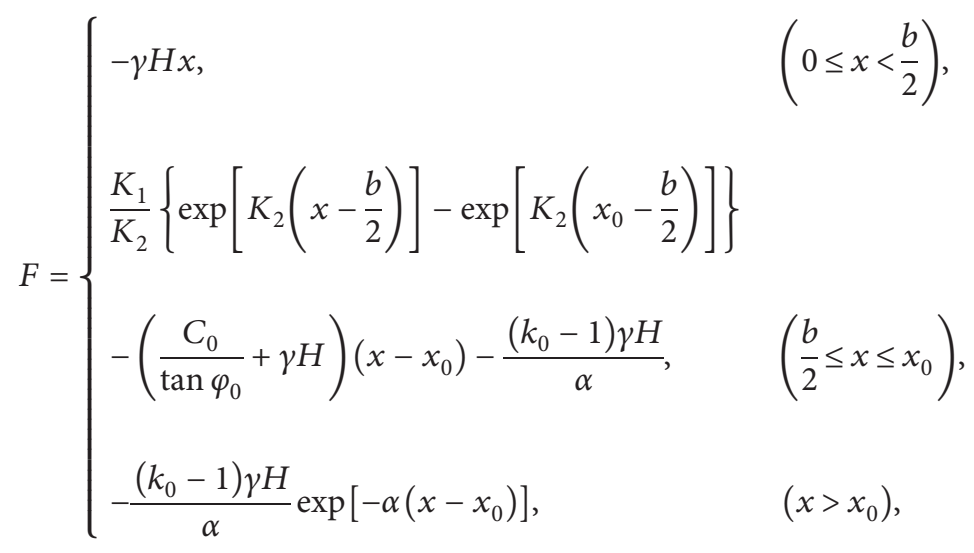


where $K_{1}$ and $K_{2}$ are parameters to be determined.
Integrating equation (5), the bending moment of the thin immediate roof under uniform load is obtained as follows:

$$
M= \begin{cases}-\gamma H \frac{x^{2}}{2}+K_{3}, & \left(0 \leq x<\frac{b}{2}\right), \\ \left(\frac{K_{1}}{K_{2}^{2}}+\frac{K_{1} h \tan \varphi_{0}}{2 K_{2}}\right) \exp \left[K_{2}\left(x-\frac{b}{2}\right)\right]-\frac{K_{1}}{K_{2}} \exp \left[K_{2}\left(x_{0}-\frac{b}{2}\right)\right] x & \\ -\left(\frac{C_{0}}{\tan \varphi_{0}}+\gamma H\right)\left(\frac{x^{2}}{2}-x x_{0}\right)-\frac{\left(k_{0}-1\right) \gamma H}{\alpha} x+K_{4}, & \left(\frac{b}{2} \leq x \leq x_{0}\right), \\ \frac{\left(k_{0}-1\right) \gamma H}{\alpha^{2}} \exp \left[-\alpha\left(x-x_{0}\right)\right]-\frac{K_{1} h \tan \varphi_{0}}{2 K_{2}} \exp \left[K_{2}\left(-x-\frac{b}{2}+2 x_{0}\right)\right], & \left(x>x_{0}\right),\end{cases}
$$

where $K_{3}$ and $K_{4}$ are parameters to be determined.

The moments of the thin immediate roof continue when $x=b / 2$ and $x=x_{0}$. Following equation (6), $K_{3}$ and $K_{4}$ are calculated as follows:

$$
\begin{aligned}
& K_{3}=K_{4}+\frac{K_{1}}{K_{2}^{2}}+\frac{K_{1} h \tan \varphi_{0}}{2 K_{2}}-\frac{b K_{1}}{2 K_{2}} \exp \left[K_{2}\left(x_{0}-\frac{b}{2}\right)\right]-\frac{C_{0} b^{2}}{8 \tan \varphi_{0}}+\frac{b x_{0}}{2}\left(\frac{C_{0}}{\tan \varphi_{0}}+\gamma H\right)-\frac{b\left(k_{0}-1\right) \gamma H}{2 \alpha}, \\
& K_{4}=\frac{\left(k_{0}-1\right) \gamma H}{\alpha}\left(\frac{1}{\alpha}+x_{0}\right)-\left(\frac{K_{1}}{K_{2}^{2}}+\frac{K_{1} h \tan \varphi_{0}}{K_{2}}\right) \exp \left[K_{2}\left(x_{0}-\frac{b}{2}\right)\right]+\frac{K_{1}}{K_{2}} \exp \left[K_{2}\left(x_{0}-\frac{b}{2}\right)\right] x_{0}-\frac{x_{0}^{2}}{2}\left(\frac{C_{0}}{\tan \varphi_{0}}+\gamma H\right) .
\end{aligned}
$$

The horizontal stress of the thin immediate roof at the roadway width is obtained as follows:

$$
\sigma_{q t}=\frac{K_{3}-\gamma H\left(x^{2} / 2\right)}{W}-\frac{2 K_{1}}{h K_{2}} \tan \varphi_{0} \exp \left[K_{2}\left(x_{0}-\frac{b}{2}\right)\right]+\frac{K_{1}}{h K_{2}} \tan \varphi_{0} .
$$

Considering the impact of the lateral loads on the thin immediate roof, the horizontal stress is calculated as follows:

$$
\begin{aligned}
\sigma_{q t}= & \frac{K_{3}-\gamma H\left(x^{2} / 2\right)}{W}-\frac{2 K_{1}}{h K_{2}} \tan \varphi_{0} \exp \left[K_{2}\left(x_{0}-\frac{b}{2}\right)\right] \\
& +\frac{K_{1}}{h K_{2}} \tan \varphi_{0}+\lambda \gamma H .
\end{aligned}
$$

2.2.3. Deposition of the Thin Immediate Roof under Uniform Load of Rectangular Coal Roadway. The deposition of the thin immediate roof at the roadway width satisfies the following equation:

$$
E I w^{\prime \prime}=M \mathrm{~d} x
$$

where $w$ is the deflection of the thin immediate roof (the deposition), $m$; $E$ is the elastic modulus of the thin immediate roof, $\mathrm{GPa}$; and $I$ is the moment of inertia, $m_{4}$.
The thin immediate roof adopts a symmetric structure with a zero-center tangle. The deposition of the roof is calculated based on equation (10) as follows:

$$
E I w=\iint M \mathrm{~d} x+K_{5}
$$

where $K_{5}$ is a parameter to be determined.

This problem is an infinite statically indeterminate problem, requiring the determination of the vertical displacement of the coal bodies on both sides before the solution. To simplify the calculation, assuming that the deformation somewhere in the coal body is zero as the deformation coordination condition, the following equation is obtained:

$$
K_{5}=-\frac{x_{q}^{2}}{2} K_{3}+\gamma H \frac{x_{q}^{4}}{24}
$$

where $x_{q}$ is the point where the deformation is assumed at zero in the plastic zone.

$x_{q}$ depends on the width of the plastic zone within the coal seam. When the hardness of the coal is high, a relatively smaller value of $x_{q}$ is selected, which is equivalent to the half of the roadway width. In case of low hardness, the point with zero deformation migrates to the deep area of the coal seam, resulting in the following equation: 


$$
x_{q}=\frac{2}{b}+\frac{m}{2 \tan \varphi_{0}}\left(\frac{1-\sin \varphi}{1+\sin \varphi}\right) \ln \left[\frac{\eta \gamma H+\left(C_{0} / \tan \varphi_{0}\right)}{C_{0} / \tan \varphi_{0}+(1+\sin \varphi / 1-\sin \varphi) P_{x}+2 C \cos \varphi / 1-\sin \varphi}\right]
$$

where $\eta$ is a parameter to be determined.

The deposition of the roof is calculated as follows:

$$
w=\frac{x^{2}-x_{q}^{2}}{2 E I} K_{3}+\gamma H \frac{x_{q}^{4}-x^{4}}{24 E I} \text {. }
$$

Under the panel strain, the deposition of the roof is calculated as follows:

$$
w=\frac{1-\mu^{2}}{2 E I} K_{3}\left(x^{2}-x_{q}^{2}\right)+\frac{1-\mu^{2}}{24 E I} \gamma H\left(x_{q}^{4}-x^{4}\right) .
$$

\section{Numerical Calculations and Verification of the Stress of the Thin Immediate Roof under Uniform Load of Rectangular Coal Roadway}

A model was established based on FLAC3D, whose dimension is $100 \times 30 \times 1 \mathrm{~m}$. The dimension of the road is $4.8 \times 4 \mathrm{~m}$ with a $3 \mathrm{~m}$ roof and $23 \mathrm{~m}$ bottom, constituting a total of 36,000 units, as shown in Figure 3. The top, bottom, left, and right sides of the model are fixed with an evenly distributed load of $2.5 \mathrm{MPa}$ at the top, excluding the weight of the coal seam.

The vertical stress and horizontal stress of the thin immediate roof under the evenly distributed load are demonstrated in Figure 4.

As shown in Figure 4, the peak coefficient of lateral support stress was 1.75 with a plastic zone width at $3.72 \mathrm{~m}$ through the theoretical calculation. In the case of $5.8 \mathrm{~m}$ thickness of the think immediate roof, the numerical calculation suggested that the vertical stress peak coefficient of the thin immediate roof was 1.64 , while the theoretical calculation indicated a plastic zone width at $3.46 \mathrm{~m}$. The theoretical and numerical calculations were compared and are illustrated in Figure 5.

As demonstrated in Figure 4, the horizontal stress of the thin immediate roof is consistent, including the theoretically calculated result and the numerically calculated result at $5.8 \mathrm{~m}$ thickness of the thin immediate roof. The maximum difference was limited to $0.67 \mathrm{MPa}$. However, in the case of $3 \mathrm{~m}$ thickness of the thin immediate roof, the maximum difference was as high as $5.2 \mathrm{MPa}$.

The relatively large difference at $3 \mathrm{~m}$ thickness of thin immediate roof is caused by the selected value of $\alpha$. In the theoretical calculation, $\alpha$ was obtained based on the counterbalance of the lateral vertical stress of the contact surface, whose curve was divided into two sections: positive exponential function on the left and negative exponential function on the right. However, the numerical calculation suggests that the aforementioned curve was followed at $5.8 \mathrm{~m}$ thickness of the thin immediate roof. When the thickness of the thin immediate roof was $3 \mathrm{~m}$, fluctuation was observed around the stress peak. The positive lateral vertical stress was selected. Figure 6 provides the detailed distribution of the lateral vertical stress.
According to Figure 6, when the thickness of the thin immediate roof was $3 \mathrm{~m}$, fluctuation was observed around the stress peak. The stress fluctuation resulted in the tolerances of the calculation of parameter $\alpha$, leading to the tolerance of the lateral vertical stress distribution. To resolve this issue, a correction factor was introduced. The comparison of the corrected result and the numerical calculation was conducted and is illustrated in Figure 7.

According to Figure 7, at the correction factor of 1.5, two calculations yielded the closest results. Therefore, for the thin immediate roof, the tolerance caused by the fluctuation of the vertical stress needs to be corrected for obtaining an accurate result.

\section{Analysis of the Collapse Mechanism of the Thin Immediate Roof under Uniform Load of Rectangular Coal Roadway}

A thinner immediate roof under uniform load leads to a higher possibility of normal section failure. On the other hand, a thicker immediate roof under uniform load leads to a higher possibility of an oblique section failure. The following analysis is conducted from two perspectives including the normal section and the oblique section.

\subsection{Analysis of the Normal Section Collapse Mechanism of the Thin Immediate Roof under Uniform Load of Rectangular Coal Roadway}

4.1.1. Forces on the Normal Section of the Thin Immediate Roof under Uniform Load. When the load imposed on the thin immediate roof under uniform load is relatively small, the internal moment is relatively small in the thin immediate roof, whose forces are similar to the homogeneous elastomer beams. The stress distribution of the pressurized zone and tensile zone forms a triangle shape, as demonstrated in Figure 8(a).

When the load imposed on the thin immediate roof under uniform load increases, the stress distribution of the tensile zone tends to bend instead of staying as a straight line, which is due to a higher compression capacity of the rock than the tensile capacity. The curve of the tensile zone stress distribution develops toward the neutral axis. When the moment reaches the strain limit of the tensile zone boundary, the normal section will break, as demonstrated in Figure $8(\mathrm{~b})$. At this moment, the stress distribution of the pressurized zone is still close to a triangle shape, while the stress distribution of the tensile zone has developed into a curve.

The key to preventing the failure of the normal section of the thin immediate roof lies in controlling the stratum strain at the bottom. The truss structure or anchor bolts (cables) along with the steel belts can be used. The ideal situation is to ensure that the thin immediate roof experiences failures 


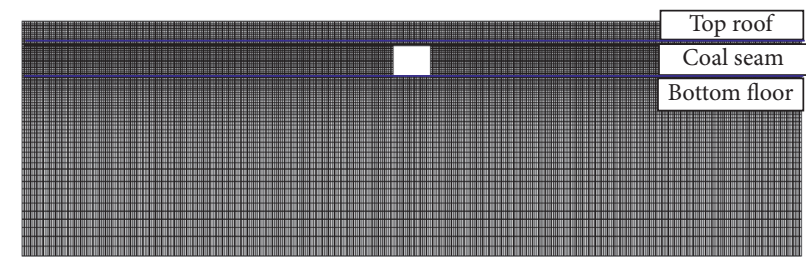

Figure 3: Numerical model of stress of thin immediate roof under uniform load.

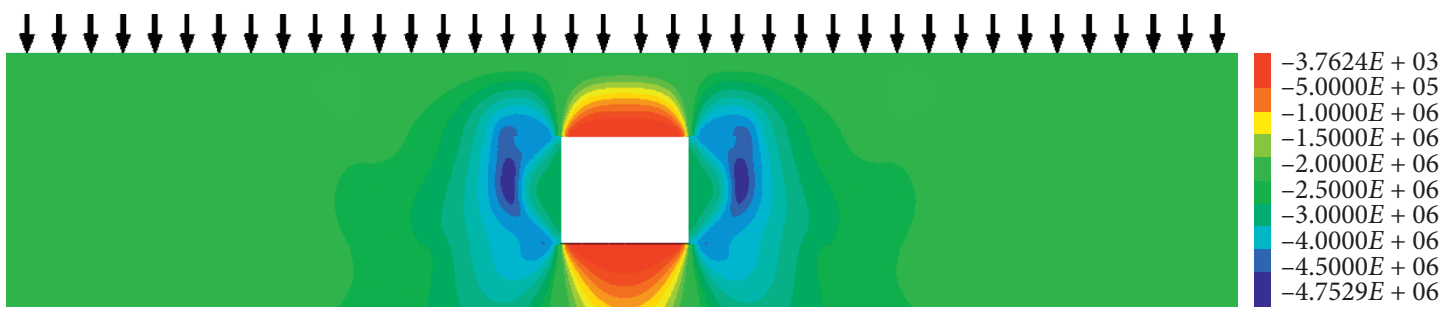

(a)

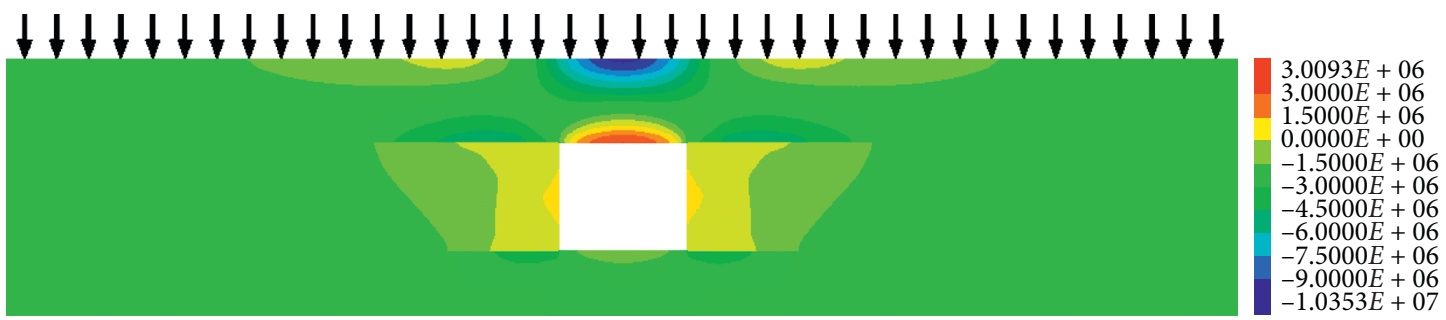

(b)

Figure 4: The stress of thin immediate roof under uniform load. (a) The cloud diagram of the vertical stress. (b) The cloud diagram of the horizontal stress.

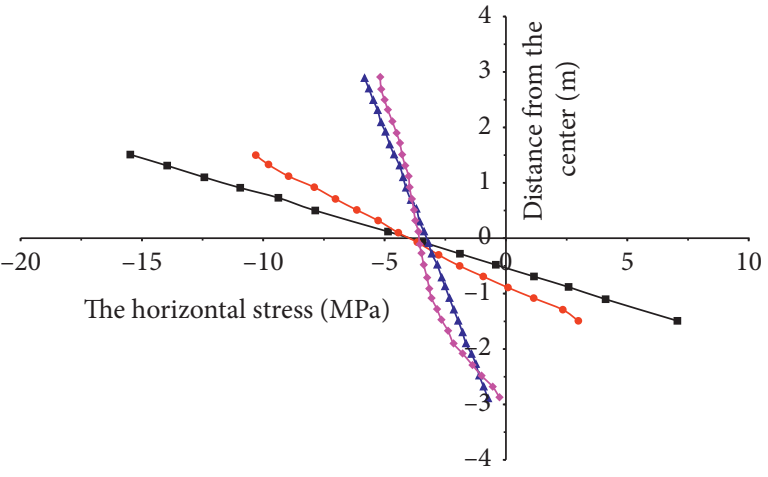

- Theoretical calculation $(3.0 \mathrm{~m})$

$\rightarrow$ FLAC 3D $(3 \mathrm{~m})$

$\leftarrow$ Theoretical calculation $(5.8 \mathrm{~m})$

$\rightarrow$ FLAC 3D $(5 \mathrm{~m})$

FIGURE 5: The horizontal stress at the center of thin immediate roof under uniform load.

simultaneously in the pressurized zone and tensile zone, making full use of the self-bearing capacity of the rock stratum. When cracks develop at the lower section of the thin immediate roof, the load born by the tensile zone is transferred to the tie rods or steel belts (reference to the steel

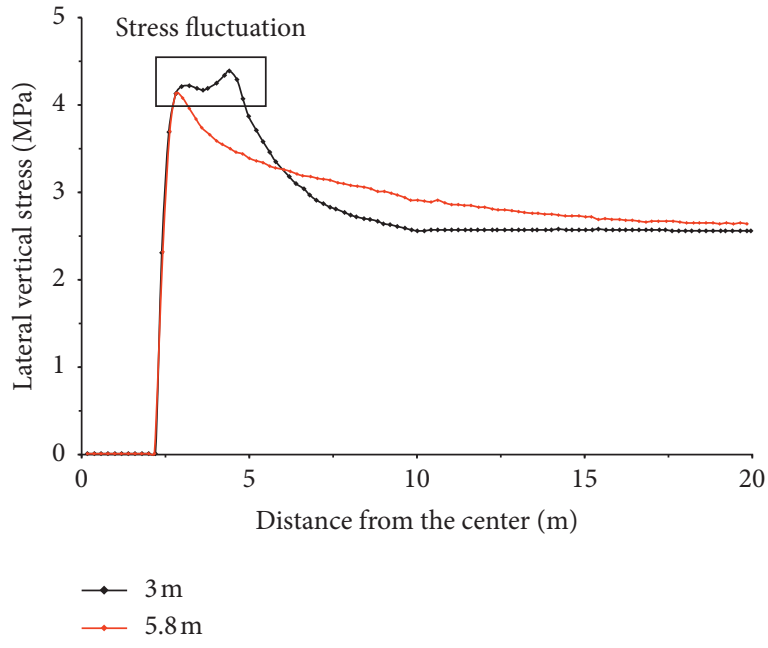

FIGURE 6: The lateral vertical stress.

bar mechanism in the steer bar and concrete beam construction; and the tie rods in the truss structure or the steel belts and ladder beams in the standard anchor bolts are equivalent to the tensile reinforcement steel bars in the steel bar and concrete structure). The tie rods or steel belts tend to bear higher forces. Meanwhile, the neutral axis moves upward, transferring the tensile force to the tie rods and steel 


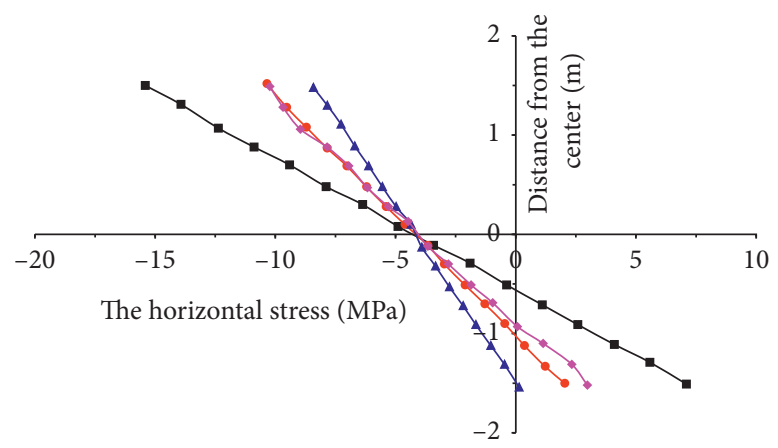

- Without correction

$\rightarrow$ Without correction factor of 1.5

$\rightarrow$ Without correction factor of 2

$\rightarrow$ FLAC 3D

Figure 7: The corrected horizontal stress distribution at the center of thin immediate roof under uniform load.

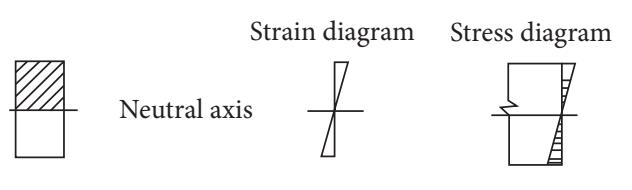

(a)

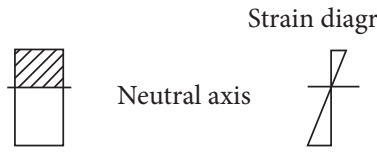

(c)

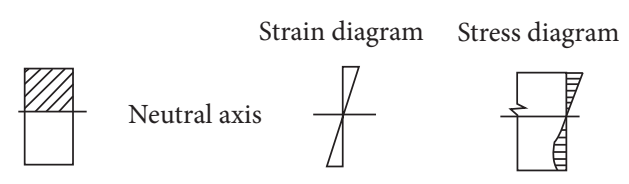

(b)

Strain diagram Stress diagram

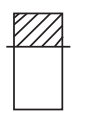

Neutral axis

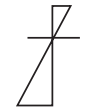

(d)

Figure 8: The mechanical characteristic of normal section of thin immediate roof under uniform load.

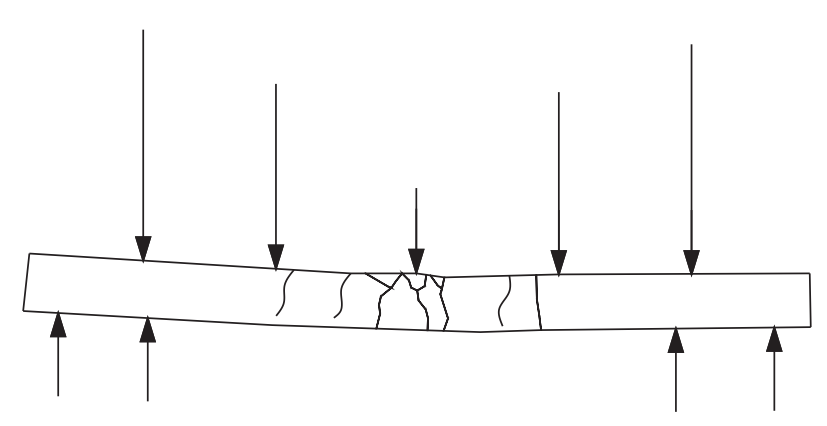

(a)

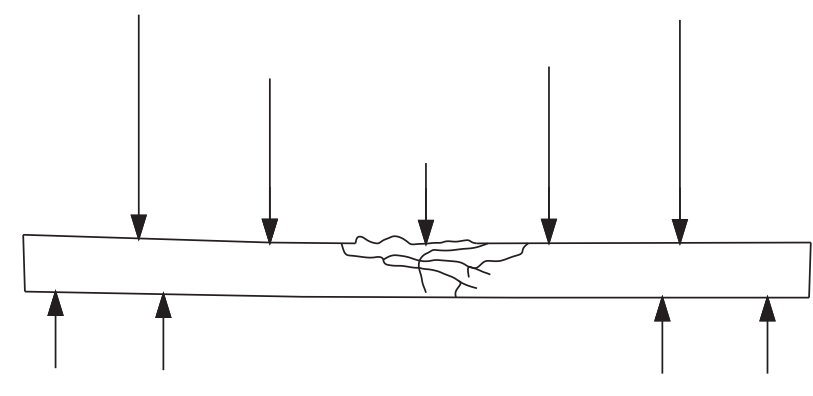

(b)

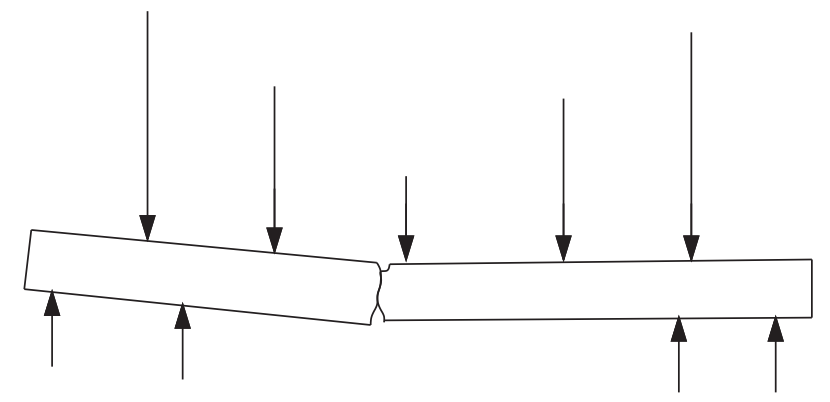

(c)

FiguRE 9: The failure form of normal section of thin immediate roof under uniform load. (a) The under-reinforced beam failure. (b) The over-reinforced beam failure. (c) The low-reinforced beam failure. 


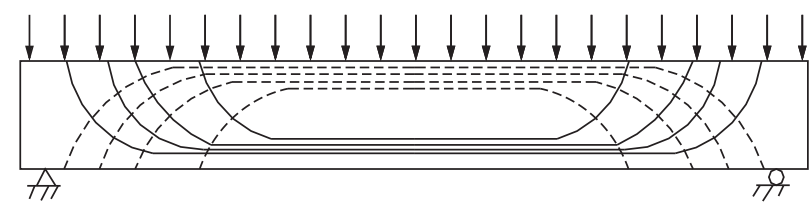

FIGURE 10: The principal stress trajectory of thin immediate roof under uniform load.
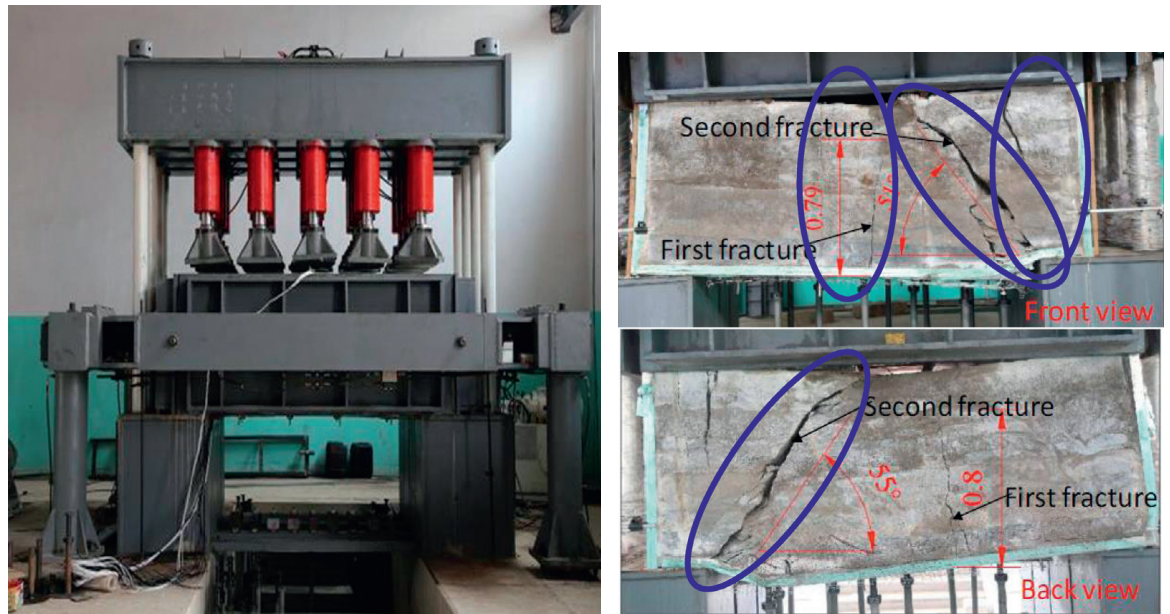

(a)

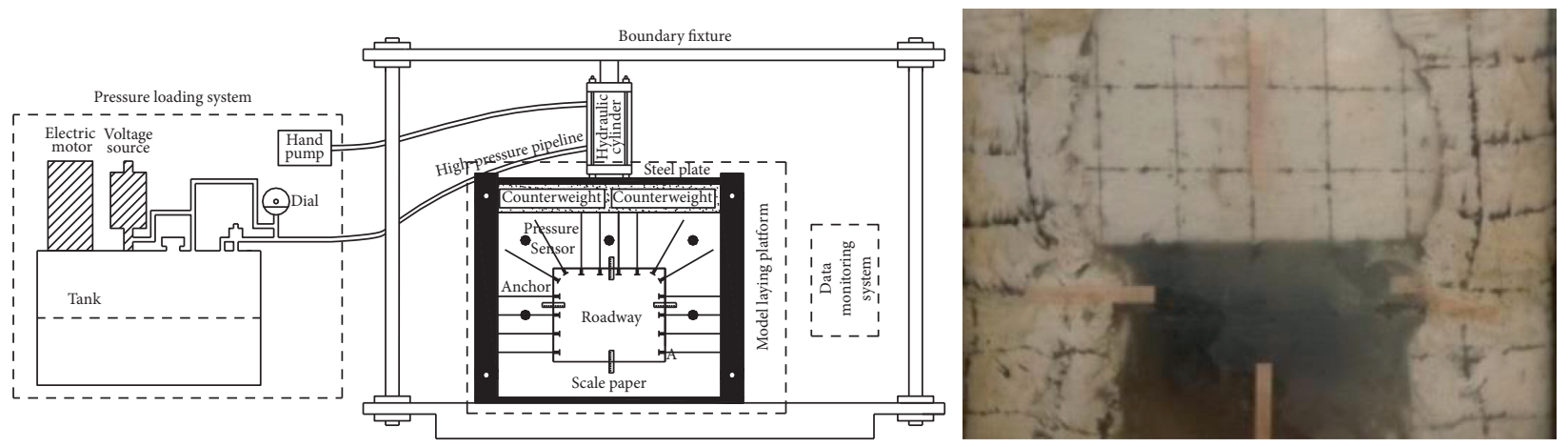

(b)

Research on key technology of surrounding rock control of $1905 \mathrm{~S}$ backstoping face in Changcheng No.3 Mine
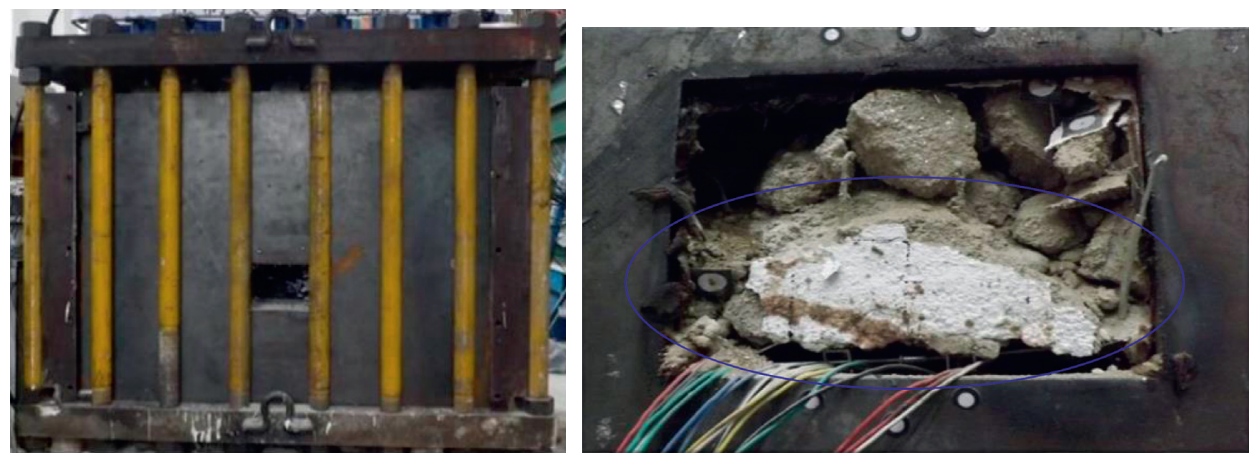

(c)

FIGURE 11: The experiment validation of oblique section failure of thin immediate roof under uniform load. (a) The test device and the failure of the thin immediate roof in the literature [20]. (b) The test device and the failure of the thin immediate roof in the literature [1]. (c) The roof collapse of the Great Wall Number \#3 coal mining field. 
belts. The loaded stratum demonstrates more plastic features, resulting in a curved stress distribution, as demonstrated in Figure 8(c).

When the load imposed on the thin immediate roof under uniform load reaches extreme, the tie rods or steel belts tend to yield, leading to the drastic deposition of the thin immediate roof and section failure, as demonstrated in Figure 8(d).

\subsubsection{Collapse Mechanism of the Thin Immediate Roof under} Uniform Load. Referencing the failures of the concrete beams, the collapses of the thin immediate roof can be divided into three categories: the under-reinforced beam failure, the over-reinforced beam failure, and the lowreinforced beam failure, as shown in Figure 9.

The under-reinforced beam failure is featured with the early yield of the tie rods or the steel belts. The section does not break until the stratum edge of the load zone is crushed, which is categorized as the ductile failure. The tie rods and steel belts demonstrated drastic plastic deformation during the process, leading to the deposition of the thin immediate roof, as demonstrated in Figure 9(a). This type of failure is often accompanied with early warnings. The over-reinforced beam failure is featured with the early crushing of the stratum in the load zone without the yield of the tie rods or steel belts. The failure occurs suddenly due to the crushing of the stratum without any clear warning, which is categorized as the brittle failure, as demonstrated in Figure 9(b). For the low-reinforced beam failure, the failure occurs once the tensile rock stratum develops cracks, which is categorized as the brittle failure, as demonstrated in Figure 9(c).

4.2. Collapse Mechanism Analysis of the Thin Immediate Roof under Uniform Load of Rectangular Coal Roadway. The principal tensile stress and load stress on the thin immediate roof under uniform load can be expressed, respectively, as follows:

$$
\begin{gathered}
\sigma_{t p}=\frac{\sigma_{q t}}{2}+\sqrt{\frac{\sigma_{q t}^{2}}{4}+\tau_{q t}^{2}}, \\
\sigma_{c p}=\frac{\sigma_{q t}}{2}-\sqrt{\frac{\sigma_{q t}^{2}}{4}+\tau_{q t}^{2}},
\end{gathered}
$$

where $\sigma_{t p}$ is the principal tensile stress, $\mathrm{MPa}$, and $\sigma_{c p}$ is the principal load stress, MPa.

When overlooking the impact of the bottom lateral shear stress load on the internal shear stress, the shear stress at the center of the thin immediate roof can be expressed as follows:

$$
\tau_{q t}=\frac{F}{8 I} h^{2}=\frac{3 F}{2 h},
$$

where $\tau_{q t}$ is the shear stress of the thin immediate roof, MPa.

The angle between the principal tensile stress and the beam axis can be expressed as follows:

$$
\tan \left(2 \alpha_{q t}\right)=-\frac{\tau_{q t}}{2 \sigma_{q t}}=-\frac{3 F}{\sigma_{q t} h},
$$

where $\alpha_{q t}$ is the angle between the principal tensile stress and the axis.

The principal stress trajectory of thin immediate roof under uniform load can be described in Figure 10.

The low positive stress and high shear stress were observed at the neutral axis with a $45^{\circ}$ principle tensile stress direction. When the load increased at the thin immediate roof to reach the tensile limit of the stratum, cracks developed. Oblique cracks were developed along the principle vertical tensile stress in the abdominal area, which was named as abdominal shear oblique cracks. From the principal stress trajectory, the principle tensile stress closer to the roadway was dominated by the horizontal direction. Without any additional support, short and vertical cracks tend to develop, slowly expanding to the load zone, which are called bending shear diagonal cracks.

The shear-span ratio reflects the relative ratio of normal stress and shear stress on the oblique section, indicating the relative ratio of the bending moment of the section to the shear force to some extent, which holds a deciding meaning to the failure of the oblique section and can be expressed as follows:

$$
\vartheta=\frac{M}{F h},
$$

where 9 is the shear-span ratio.

Introducing equations (5) and (6) into equation (19), the following equation is obtained:

$$
\vartheta=\frac{x}{2 h}-\frac{K_{3}}{\gamma H x h} \text {. }
$$

Around the center of the thin immediate roof, the moment plays a vital role in the roof failure, leading to high possibilities of normal section failure. Due to the lower shear-span ratio at both roof sides, the principal stress trajectory follows a pattern of short cylinders, leading to high possibilities of oblique section failure. In other words, the stratum in the oblique section tends to be sliced into small oblique cylinder units by the abdominal shear oblique cracks, ending with the ultimate failure. The load bearing capability is relatively high for this type of failure, which depends on the load strength of the stratum and is categorized as the brittle failure.

Some previously conducted experiments have also verified the oblique failures of the thin immediate roof under uniform load, as demonstrated in Figure 11. In spite of some deviations from the test conditions and the theoretical calculation, the general pattern and rule demonstrated are consistent.

In the simulation demonstrated in Figure 11(a), small cracks developed in the thin immediate roadway roof, suggesting the normal section failure of the thin immediate roof. However, due to the constraint generated from the steel belts, the crack development was limited to a relatively small width. The principle tensile stress led to the failure of the 


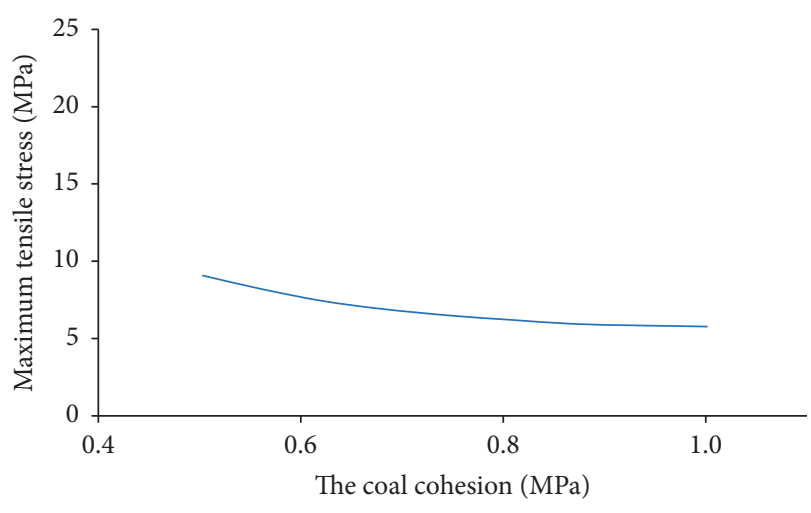

(a)

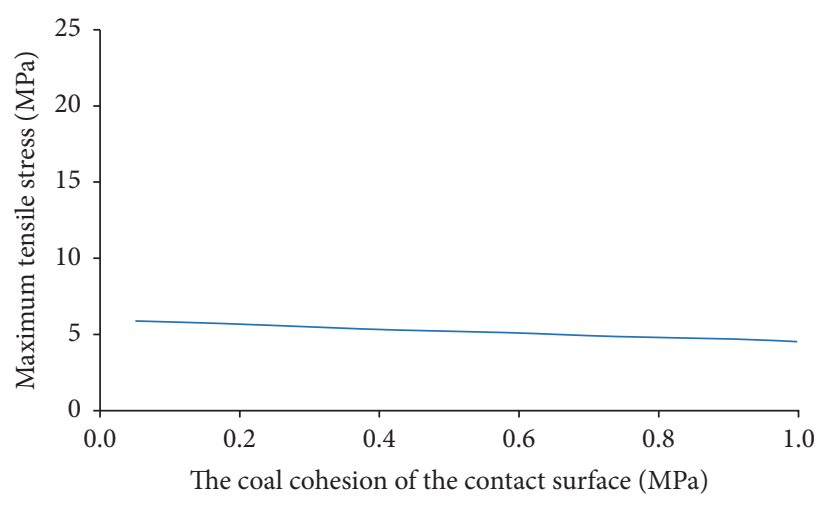

(c)

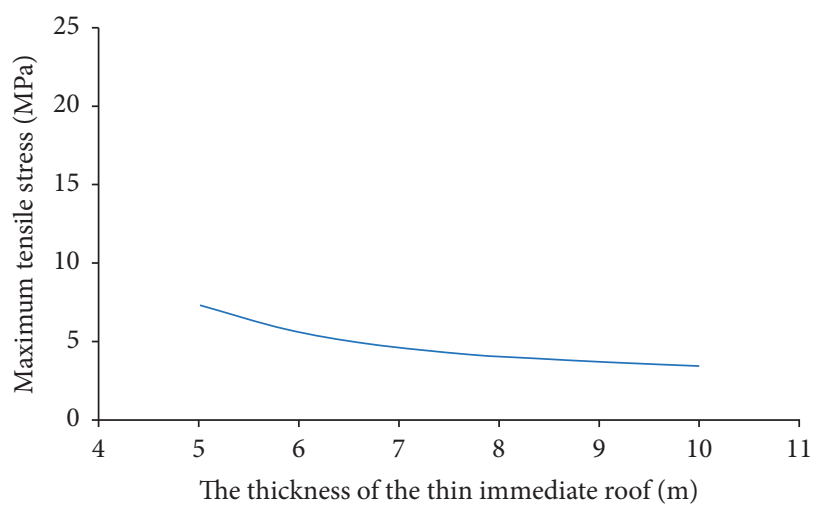

(e)

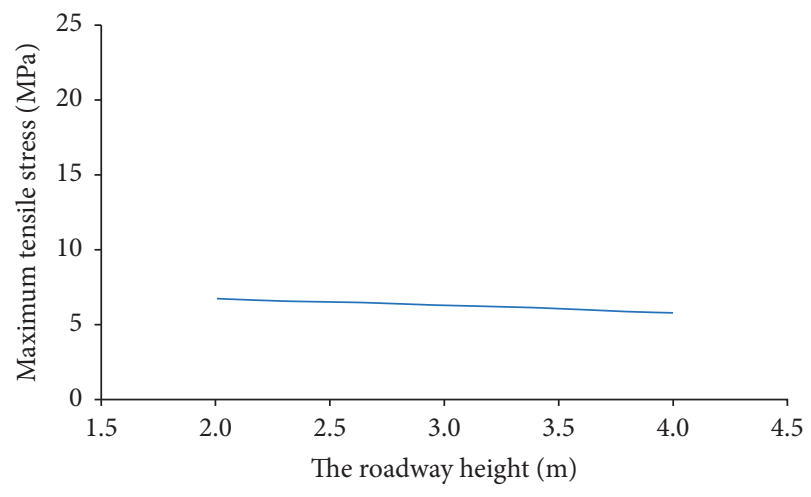

(g)

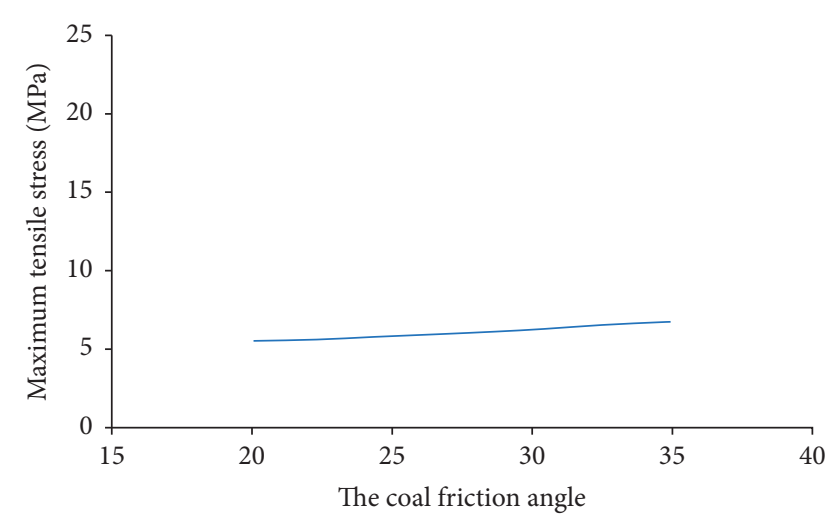

(b)

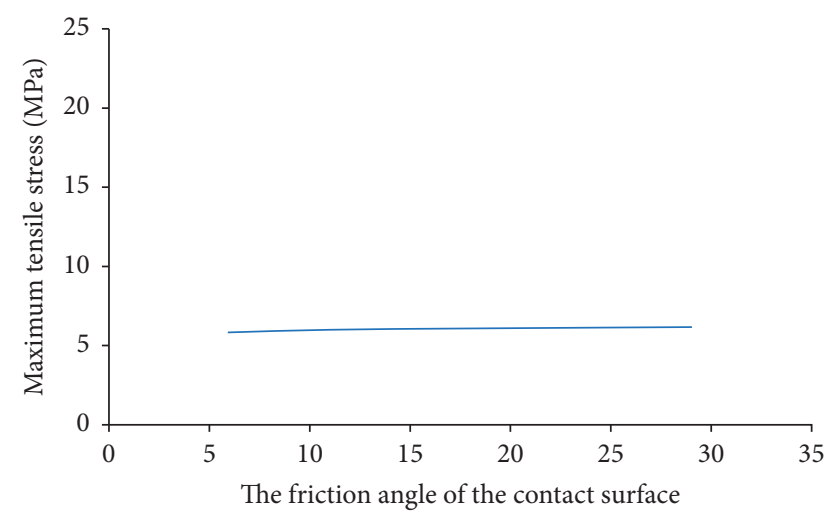

(d)

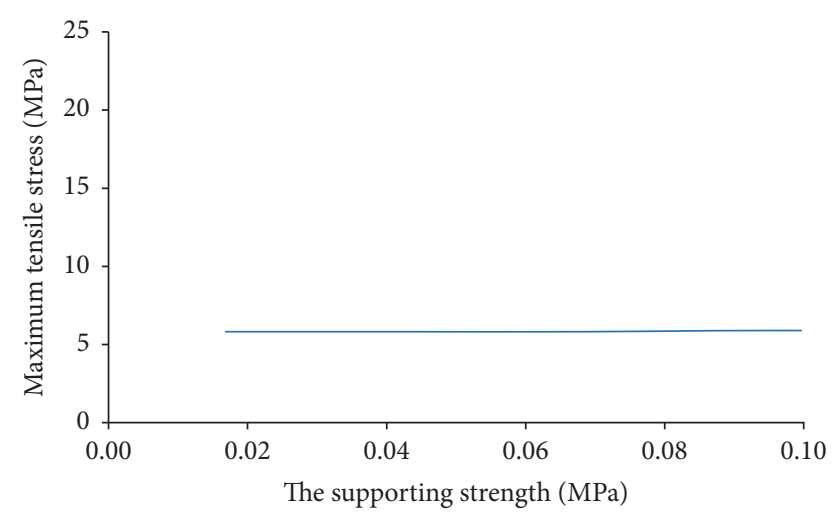

(f)

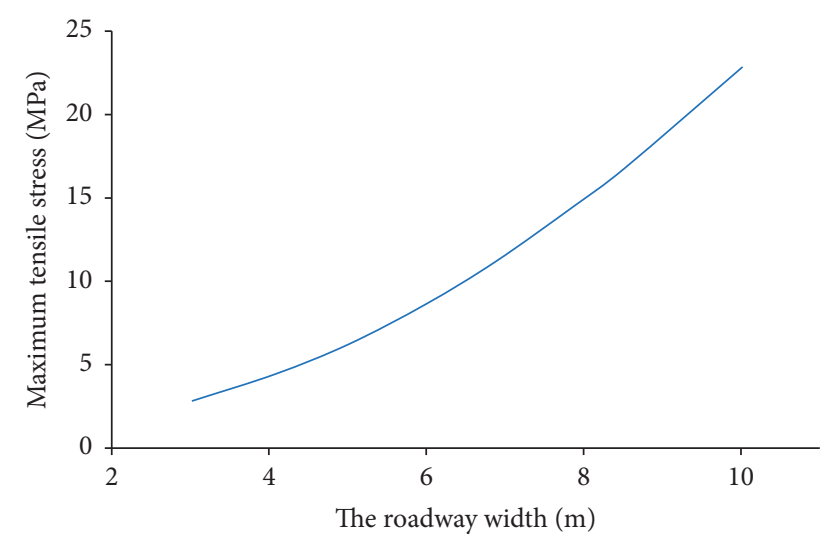

(h)

Figure 12: Parameter analysis of maximum tensile stress of thin immediate roof under uniform load. (a) The coal cohesion. (b) The coal friction angle. (c) The coal cohesion of the contact surface. (d) The friction angle of the contact surface. (e) The thickness of the thin immediate roof. (f) The supporting strength. (g) The roadway height. (h) The roadway width. 


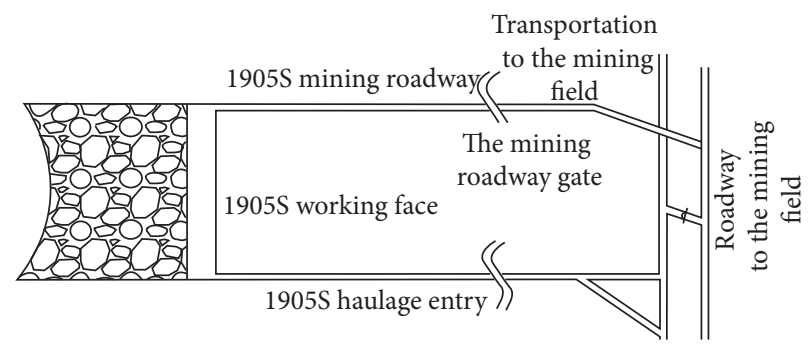

FIGURE 13: Layout of 1905 S working face.

TABle 1: Properties of coal and immediate roof of 1905 S entry.

\begin{tabular}{lcccccc}
\hline Stratum & Thickness $(\mathrm{m})$ & $\begin{array}{c}\text { Tensile strength } \\
(\mathrm{MPa})\end{array}$ & $\begin{array}{c}\text { Compressive } \\
\text { strength }(\mathrm{MPa})\end{array}$ & $\begin{array}{c}\text { Elastic modulus } \\
(\mathrm{GPa})\end{array}$ & $\begin{array}{c}\text { Poisson's ratio } \\
(\mathrm{MPa})\end{array}$ & $\begin{array}{c}\text { Cohesion } \\
\text { Internal friction } \\
\text { angle }\left({ }^{\circ}\right)\end{array}$ \\
\hline Immediate roof & 1.8 & 5.09 & 98.75 & 46.3 & 0.22 & 8.47 \\
Coal seam & 4.0 & - & 4.39 & 7.86 & 0.31 & 33.9 \\
\hline
\end{tabular}

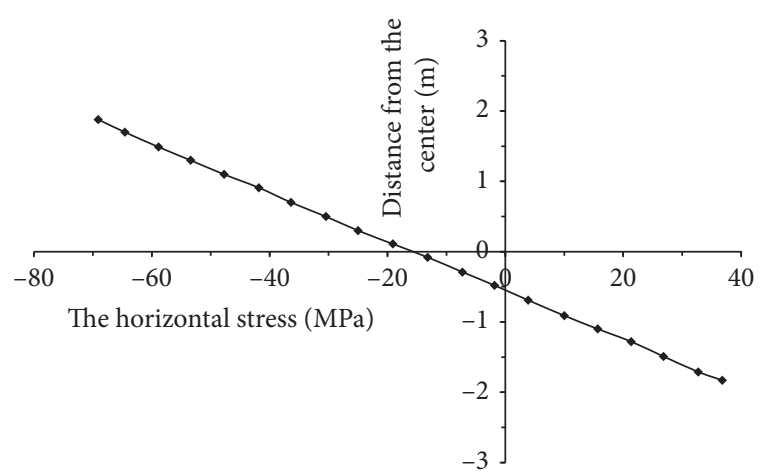

Figure 14: Horizontal stress in the middle of 1905 S air-return entry.

oblique section, which is similar to the failure of the oblique load. Clear damaged stratum can be observed in the front view in the right bottom corner of the roof. After the failure, the cracks continued to grow driven by the principle tensile stress. Due to the inclined anchor bolts, no collapse occurred; only cracks occurred. The experiment demonstrated in Figure 11(b) simulated the roadway sides and the roof. Compared with Figure 11(a), the following differences were observed. (1) No crack was observed in the roof center due to unevenly distributed load caused by different loading methods, resulting in a low load in the center and high loads at sides. (2) The oblique cracks at the roof bottom moved toward the center. The roadway movement can be evaluated based on the black lines marked in Figure 11(b), suggesting that the roadway movements had some impact on the crack development of the thin immediate roof and further influenced the stability of the thin immediate roof, which failed to be included in the theoretical calculation mentioned above. Figure 11(c) demonstrates the physical simulation tests to the hard and thin roof. Five times of the original vertical stress (the original vertical stress was about $17.5 \mathrm{MPa}$ ) was imposed on the roof, resulting in the development of the through oblique cracks. Despite the anchor bolts, collapse still occurred in arch shapes. Three experiments illustrate the failures of the oblique section of the thin immediate roof. The development of the through oblique cracks without sufficient supports can lead to roof collapse.

\section{Parameter Analysis of the Maximum Tensile Stress of the Thin Immediate Roof under Uniform Load of Rectangular Coal Roadway}

The maximum tensile stress for the thin immediate roof locates at the center of the thin immediate roof. When the tensile stress exceeds the tensile strength of the stratum, the normal section failure can occur easily. Therefore, the maximum tensile stress at the roof center was selected for parameter analysis with the roof thickness of $5.8 \mathrm{~m}$ to avoid the lateral vertical stress fluctuation, as demonstrated in Figure 12 . The basic parameters are the same as those included in the numerical calculation model.

According to Figure 12, when other parameters stay unchanged, (1) the coal internal friction angle and the cohesion, the friction angle and the cohesion of the contact surface, the support strength $(0 \sim 0.1 \mathrm{MPa})$, and the roadway height have limited impact on the maximum tensile stress; (2) the thickness of the thin immediate roof has a relatively high impact on the maximum tensile stress; and as the roof thickness increases, the maximum tensile stress decreases accordingly; the classic beam theory is no longer applicable for the roof with extreme thicknesses due to the increased tolerances; (3) the roadway width has a significant impact on the maximum tensile stress of the thin immediate roof; as the roadway width increases, the maximum tensile stress increases approximately linearly. 
TABLE 2: Rock bolt support parameters of 1905 S roadway.

\begin{tabular}{|c|c|c|c|c|c|c|c|c|c|c|}
\hline \multirow[b]{2}{*}{ Parameter } & \multicolumn{5}{|c|}{ Anchor bolt } & \multicolumn{5}{|c|}{ Anchor cable } \\
\hline & $\begin{array}{c}\text { Length } \\
(\mathrm{mm})\end{array}$ & $\begin{array}{c}\text { Distance } \\
(\mathrm{mm})\end{array}$ & $\begin{array}{c}\text { Row } \\
\text { distance }(\mathrm{mm})\end{array}$ & $\begin{array}{c}\text { Diameter } \\
(\mathrm{mm})\end{array}$ & $\begin{array}{c}\text { Preload } \\
(\mathrm{kN})\end{array}$ & $\begin{array}{c}\text { Length } \\
(\mathrm{mm})\end{array}$ & Number/row & $\begin{array}{c}\text { Row } \\
\text { distance }(\mathrm{mm})\end{array}$ & $\begin{array}{c}\text { Diameter } \\
(\mathrm{mm})\end{array}$ & $\begin{array}{c}\text { Preload } \\
(\mathrm{N} \cdot \mathrm{m})\end{array}$ \\
\hline Roof & 2400 & 1200 & 1200 & 22 & 200 & 6500 & 2 & 2400 & 17.8 & 200 \\
\hline Two sides & 2400 & 1200 & 1200 & 22 & 200 & - & - & - & - & - \\
\hline
\end{tabular}

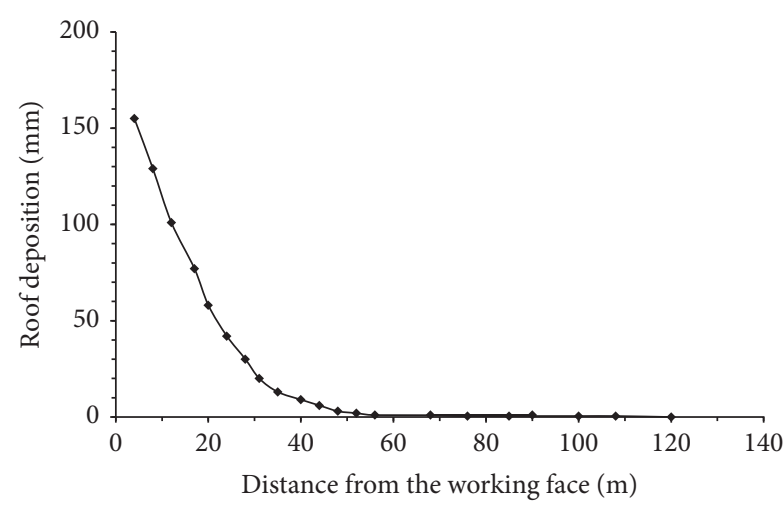

Figure 15: Roof deposition of 1905S haulage entry.

\section{Engineering Verification of the Stability of the Thin Immediate Roof under Uniform Load of Rectangular Coal Roadway}

The thin immediate roof under uniform load is mainly suitable for the roadway under the thin bedrock and the roadway with the hard-immediate roof. The engineering verification was conducted in 1905S mining roadway of Great Wall Number \#3 coal excavation field.

1905S mining roadway of Great Wall Number \#3 coal field locates at number $\# 9$ coal seam, with a total roadway length of $2665 \mathrm{~m}$, whose inclined angle is $12 \sim 24^{\circ}$, with average at $17^{\circ}$. The embedded depth of the $1905 \mathrm{~S}$ haulage entry is about $700 \mathrm{~m}$ with a $600 \mathrm{~m}$ embedded depth of the mining roadway. Solid coal is surrounding the work face. The detailed work surface is demonstrated in Figure 13.

The immediate roof of $1905 \mathrm{~S}$ mining roadway is made out of limestone, whose mechanical properties are listed in Table 1.

According to Table 1, the 1905 S roadway roof has high hardness, meeting the conditions of the thin immediate roof. However, more parameters are needed to calculate the forces born by the roof. The horizontal stress was taken by equating to the vertical stress. The coal cohesion was taken as $1 / 2$ of the coal rock block. The cohesion of the coal contact surface was taken as 1/10 of the rock block. The friction angle of the coal rock body was taken equating to the coal rock block. The friction angle in the rock contact surface is $10^{\circ}$ with the peak stress coefficient at 2 . The theoretical calculation of the horizontal stress at the center of the thin immediate roof is shown in Figure 14.

According to Figure 14, the area 1.2 meters away from the roof center is the tensile stress zone when no mining is conducted. Under mining, the roadway bore a higher load.

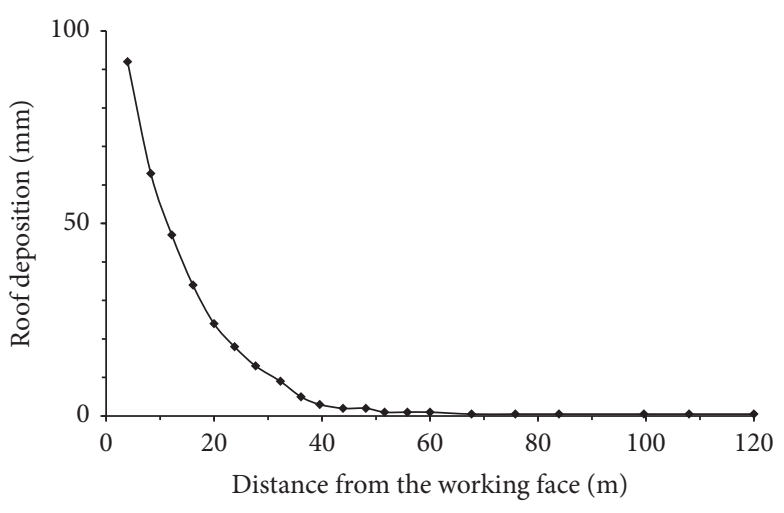

FIgURE 16: Roof deposition of 1905 S air-return entry.

The tensile stress at the lower section of the roof exceeded the tensile strength, transforming the linear distribution into a curved distribution toward the neutral axis. When the tensile stress at the tensile zone boundary reached the limit, the section tended to crack. To prevent the development of cracks, anchor bolts were installed on the site to enhance the roof stability.

The section of $1905 \mathrm{~S}$ air-returning roadway takes the shape of an oblique rectangle with a cross section width of $5400 \mathrm{~mm}$, a low top of $3910 \mathrm{~mm}$, and a high top of $4680 \mathrm{~mm}$. The roadway is supported by anchor cable and net, anchor rod is $\Phi 22 \mathrm{~mm} \times 2400 \mathrm{~mm}$ high strength bolt, steel pallet is $150 \times 150 \times 10 \mathrm{~mm}$, each anchor has two MSK2835 resin cartridges, row spacing between bolts is $1200 \times 1200 \mathrm{~mm}$, roof $W$ steel belt is $5200 \times 280 \times 3 \mathrm{~mm}$, high (low) steel belt is $2600(1400) \times 280 \times 3 \mathrm{~mm}$, top steel strand anchor cable is $\Phi 17.8 \times 6500 \mathrm{~mm}$, each with four MSK2835 resin cartridges, steel plate is $300 \times 300 \times 12 \mathrm{~mm}$, and row spacing is $2400 \mathrm{~mm}$, two per row. The main parameters of bolt support are presented in Table 2.

The actual roof depositions of the 1905 S roadway surrounding rock were measured and presented in Figures 15 and 16 .

The forces on the roof anchor bolts of the 1905S haulage entry were measured through the dynamometer on site and are presented in Figure 17.

According to Figures 15 to 17, the following results are obtained: (1) With a relatively weak anchor supporting system, the deformations of two roadways were limited under one-time excavation effect. The roof deposition of $1905 \mathrm{~S}$ haulage entry was about $180 \mathrm{~mm}$, while the $1905 \mathrm{~S}$ airreturning roadway experienced a total of $120 \mathrm{~mm}$ in deposition, which is consistent with the theoretical calculations. (2) The forces on the anchor bolts experienced limited variances 


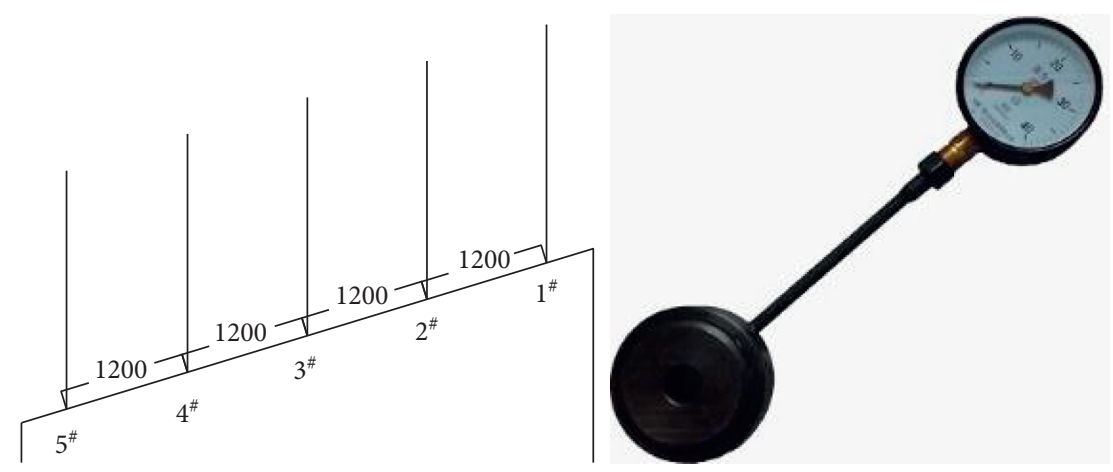

(a)

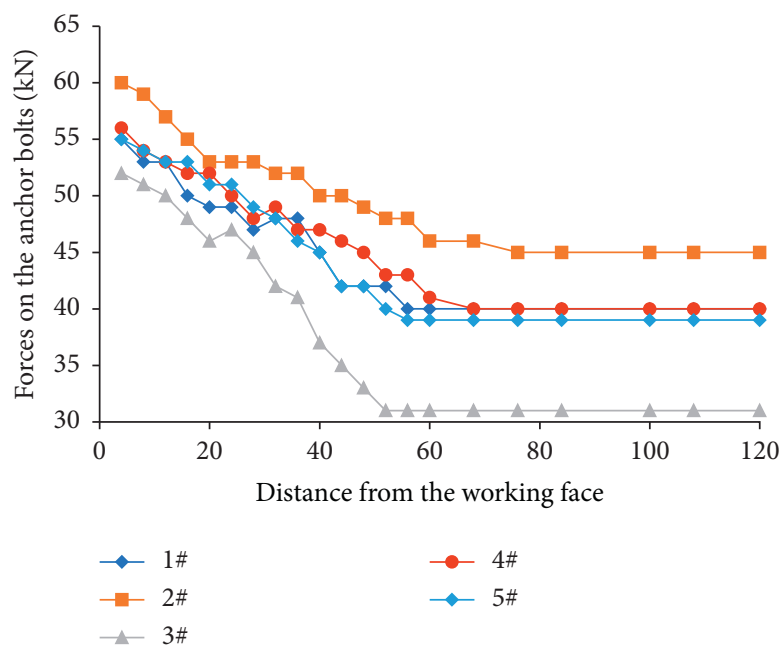

(b)

FIgURE 17: Rock bolt force of 1905 S haulage entry. (a) Bolt dynamometer and number. (b) Bolt force.

50 meters beyond the working face. The forces on the anchor bolts experienced some increases within 50 meters from the working face, as high as $30 \mathrm{kN}$. The increase was relatively small, suggesting that the vertical deformation of the surrounding rock within the supporting range of the anchor bolts was limited, validating the selection of the classical beam theory for the study of the roof stability in this study.

\section{Conclusions}

(1) The stress distribution and deposition of the thin immediate roof under uniform load of rectangular coal roadway were obtained through the theoretical calculations.

(2) The stress theoretical calculations and the numerical calculations of the thin immediate roof under uniform load were compared and a consistent trend was obtained, especially at $5.8 \mathrm{~m}$ thickness of the thin immediate roof. However, the differences between the theoretical calculations and the numerical calculations were relatively large at $3 \mathrm{~m}$ thickness of the thin immediate roof, which was caused by the fluctuations observed around the lateral supporting stress peak, resulting in tolerances among parameters. After the introduction of the correction factors, the differences were significantly reduced, rendering the consistency between the theoretical calculations and the numerical calculations.

(3) Two failures of the thin immediate roof under uniform load were identified: the normal cross section failure caused by the bottom tensile stress and the failure of the oblique section caused by the combined effect of the tensile stress in the abdominal area and compressive stress.

(4) The parameter analysis of the maximum tensile stress based on the theoretical equation reveals that the coal internal friction angle and cohesion, the friction angle and the cohesion of the contact surface, the support strength, and the roadway height have limited impact on the maximum tensile stress. The thickness of the thin immediate roof has a relatively high impact on the maximum tensile stress. As the roof thickness increases, the maximum tensile stress decreases accordingly. The classic beam theory is no longer applicable for the roof with extreme thicknesses due to the increased tolerances. The roadway width has a significant impact on the maximum tensile stress of the thin 
immediate roof. As the roadway width increases, the maximum tensile stress increases approximately linearly.

(5) The stability of the thin immediate roof under uniform load was tested and verified on the 1905S mining roadway of Great Wall Number \#3 mine. Under most of circumstances, the thin immediate roof with high hardness is stable consistently.

\section{Data Availability}

The data used to support the findings of this study are available from the corresponding author upon request.

\section{Conflicts of Interest}

The authors declare that they have no conflicts of interest regarding the publication of this paper.

\section{Acknowledgments}

This research was supported by the National Natural Science Foundation of China (Grant nos. 51674119, 51804119 and 51874133).

\section{References}

[1] W. Shen, J. Bai, W. Li, and X.-Y. Wang, "Prediction of relative displacement for entry roof with weak plane under the effect of mining abutment stress," Tunnelling and Underground Space Technology, vol. 71, pp. 309-317, 2018.

[2] Y. Yu, H. Xing, and F. Cheng, "Study on load transmission mechanism and limit equilibrium zone of coal-wall in extraction opening," Journal of China Coal Society, vol. 37, no. 10, pp. 1630-1636, 2012.

[3] Y. Zhang, L. Cheng, J. Yang, and J. Ming, "Bearing characteristic of composite rock-bolt bearing structure under different bolt support density," Journal of Mining and Safety Engineering, vol. 32, no. 2, pp. 305-309, 2015.

[4] Y. Pan, S. Gu, and Y. Qi, "Analytic solution of tight roof's bending moment, deflection and shear force under advanced supercharger load and supporting resistance before first weighting," Chinese Journal of Rock Mechanics and Engineering, vol. 32, no. 8, pp. 1544-1553, 2013.

[5] H. Kang, J. Li, J. Yang, and F. Gao, "Investigation on the influence of abutment pressure on the stability of rock bolt reinforced roof strata through physical and numerical modeling," Rock Mechanics \& Rock Engineering, vol. 50, no. 2, pp. 1-15, 2016.

[6] Z. Zhao, W. Wang, L. Wang et al., "Compression-shear strength criterion of coal-rock combination model considering interface effect," Tunnelling and Underground Space Technology, vol. 47, pp. 193-199, 2015.

[7] W. Shen, J. Bai, X. Wang, and Y. Yu, "Response and control technology for entry loaded by mining abutment stress of a thick hard roof," International Journal of Rock Mechanics and Mining Sciences, vol. 90, pp. 26-34, 2016.

[8] S. Sinha and Y. P. Chugh, "An evaluation of roof support plans at two coal mines in Illinois using numerical models," International Journal of Rock Mechanics \& Mining Sciences, vol. 82, pp. 821-829, 2016.
[9] S. Bastola and Y. P. Chugh, "Shear strength and stiffness properties of bedding planes and discontinuities in the immediate roof rocks overlying the no. 6 coal seam in Illinois," in Proceedings of the ISRM 2015, Montreal, Canada, March 2015.

[10] Y. P. Chugh and S. Sinha, "Numerical modeling of roof support plans at 4-way coal mine intersections," in Proceedings of the 49th US Rock Mechanics/Geomechanics Symposium, San Francisco, CA, USA, June 2015.

[11] B. Wang, W.-J. Wang, F.-J. Zhao et al., "Study of bolt anchoring effect based on self-bearing characteristics of roadway surrounding rock," Rock and Soil Mechanics, vol. 35, no. 7, pp. 1965-1972, 2014.

[12] N. Ma, X. Zhao, Z. Zhao et al., "Stability analysis and control technology of mine roadway roof in deep mining," Journal of China Coal Society, vol. 40, no. 10, pp. 2287-2295, 2015.

[13] L. I. Ji, N. Ma, and Z. Ding, "Heterogeneous large deformation mechanism based on change of principal stress direction in deep gob side entry and control," Journal of Mining \& Safety Engineering, vol. 35, no. 4, pp. 670-676, 2018.

[14] C. Carranza-Torres, "Analytical and numerical study of the mechanics of rockbolt reinforcement around tunnels in rock masses," Rock Mechanics and Rock Engineering, vol. 42, no. 2, pp. 175-228, 2009.

[15] R. Y. Man-chu, Application of Shi's Discontinuous Deformation Analysis to the Study of Rock behavior, Department of Civil Engineering College of Engineering University of California Berkeley, Berkeley, CA, USA, 1991.

[16] S. Chen, Q. Qian, and M. Wang, "Problems of deformation and bearing capacity of rock mass around deep buried tunnels," Chinese Journal of Rock Mechanics and Engineering, vol. 24, no. 13, pp. 2203-2210, 2005.

[17] X. Zhao, M. Cai, and M. Cai, "Mutual influence between shear dilatation ofrock mass and rebar support around underground excavation," Chinese Journal of Rock Mechanics and Engineering, vol. 29, no. 10, pp. 2056-2062, 2010.

[18] W. Wang, C. Yuan, W. Yu et al., "Stability control method of surrounding rock in deep roadway with large deformation," Journal of China Coal Society, vol. 41, no. 12, pp. 2921-2931, 2016.

[19] China University of Mining and Technology, CHENG Liang Structure Characteristic and Stability Analysis Method of Rectangle Coal Roadway Roof and Engineering Validation, China University of Mining and Technology, Xuzhou, China, 2018.

[20] X. Yang, C. Hu, M. He et al., "Study on presplitting blasting the roof strata of adjacent roadway to control roadway deformation," Shock and Vibration, vol. 2019, Article ID 3174898, 16 pages, 2019. 